\title{
Hypertension among Faculty Members of Health Sciences College at South Saudi Arabia: Prevalence and Risk Factors
}

\author{
Mohammad Nazzal. Alshloul, RN, MPH, DNSc ${ }^{1}$, Abdullah Mousa. Khamaiseh, RN, MPH, DNSc ${ }^{2}$ \\ ${ }^{1}$ Al-Ghad International College for Applied Medical Sciences, PO box 305 PC 6241 Abha, KSA \\ ${ }^{2}$ Princess Muna Faculty of Nursing, Mutah University - Mutah-Kirak, Jordan
}

\begin{abstract}
Background: Essential Hypertension is a challenge for public health professionals all over the world. The aims of the present study were to determine the prevalence of hypertension among faculty members of private College and to investigate risks factors. Methods: A cross-sectional study was conducted in a private College- Saudi Arabia. The sample size was 115 members. The participants were asked to complete a self-reported questionnaire. Results: Both systolic and diastolic hypertension were significantly associated with gender and educational level (p<05). Systolic hypertension was significantly associated with age groups while diastolic hypertension was significantly associated with marital status $(p<05)$. More than two-third $(69.6 \%)$ subjects were overweight or obese. Hypertension was detected in $39.2 \%$ of participants, and obesity in $30.4 \%$. Conclusions: Factors associated with hypertension were male gender, educational level, and older age group. This study highlighted the needs for more studies to detect hypertension and explore other risk factors.
\end{abstract}

Keywords: Prevalence, Essential Hypertension, Risk factors, Abha

\section{Background}

Hypertension (HTN) is a considered as important public health issue all over the world ${ }^{(1)}$. Epidemiological literature indicated that HTN is the principal and most essential modifiable risk factor for congestive heart failure, coronary heart disease, stroke, retinopathy, and renal diseases ${ }^{(2,3)}$. Indeed, according to the American Heart Association statistics, HTN is the third 'killer', accounting for one in every eight deaths worldwide ${ }^{(4)}$.

Throughout the previous twenty years, the Kingdom of Saudi Arabia has experiencing important socio-economic expansion leading to significant alterations in its lifestyle and the standard of living (5). Furthermore, these transformations have resulted in variations in social practices and related dietary habits, several of which are not certainly healthy ones ${ }^{(6)}$. The lack of exercise and widespread of sedentary habits among large segments of the society have additionally complicated this public health issue (7). These reported factors and other investigated risk factors, in the public health literature, have facilitated the development of degenerative diseases of adult life such as HTN obesity AND diabetes mellitus (5). Such medical conditions have essentially replaced communicable diseases as the principal cause for morbidity and mortality ${ }^{(6,7)}$.

In the Middle East Region, HTN is estimated to affect $20 \%-26 \%$ of the population above 35 years of age (Tarver, 2014). In Saudi Arabia, studies have estimated its prevalence among adults to range from $4 \%$ to $15 \%{ }^{(8,9,10)}$. Nevertheless, a recent Saudi study (9) using a blood pressure (BP) of 140/90 as the diagnostic cut off point for HTN, reported that the prevalence rate for essential HTN was \% 11.8among the 2011 participants with a higher prevalence among males (73.6\%) compared to $(26.4 \%)$ females.

While it has commonly been reported that the causes of HTN are not known, this is only partially correct as the scientists have inadequate evidence about genetic variations or genes that are under-expressed or over-expressed and may cause high $\mathrm{BP}^{(11)}$. On the other hand, the literature illustrated several risk factors that may increase BP and lead to HTN. These factors may include gender, age in years, educational level, and body weight ${ }^{(9,12-14)}$. For example, Tayem et al. ${ }^{(13)}$ conducted a descriptive study to identify the possible risk factors of HTN development among students at a central university in Palestine. The results reported that HTN was more common in male $(38 \%)$ males, than females $(11.2 \%)$. Moreover, obesity was associated with HTN $(\mathrm{p}<0.001)$.

Only few studies have investigated the prevalence and associated risk factors of HTN among university staff in Saudi Arabia ${ }^{(9)}$. Tailakh et al. ${ }^{(15)}$ reported that when such data was not addressed and examined it will have negative effects on lecturer in health sciences lecturer, students, learning process and, sooner or later, prospective clients. This study is regarded as one of the initial and worthy efforts that focus on prevalence and risk factors of HTN among Faculty members of health sciences in Saudi Arabia. Moreover, this study will add further to the vastness of comprehension of the problem in the international literature from the Saudi perspective.

\section{Research Questions}

Clearly, the picture of need to determine the prevalence of HTN and its associated risk factors among faculty members at south Saudi Arabia considered vital importance to support those faculty members. Therefore, this study filled the gap in the literature by answering the following research questions: 


\section{International Journal of Science and Research (IJSR) \\ ISSN (Online): 2319-7064}

Index Copernicus Value (2015): 78.96 | Impact Factor (2015): 6.391

1) What is the prevalence rate of essential HTN among faculty members in south Saudi Arabia?

2) What are the participants' classifications of body weight measurements?

3) Do faculty members HTN status differs significantly in relation to their socio-demographics (gender, age, educational level, and body mass index)?

\section{Methods}

\section{Design}

This study utilized a descriptive correlation design to fit the study purpose. The data were collected from the participants during the second semester of 2014/2015 academic year.

\section{Sampling and Setting}

The study was conducted at a private Health Sciences College located in the south part of Saudi Arabia. A total number of 115 faculty members were recruited by using simple random sampling from attendance list. The inclusion criteria included faculty members who attended in the second semester of 2014/2015 academic year at previously selected college and agreed to participate in the study. Exclusion criteria were all those staff whose age is below than 25 years.

\section{Ethical Consideration}

The ethical principles of nursing research were sufficiently applied and maintained. The study was internally reviewed by the Academic Research Committee at the selected private health sciences college. The participants were made fully aware about the study goals, significance, participants' selection method, their right to withdraw at any time, the benefits versus risks of the study, type of required data, and the nature of commitment. All faculty members agreed to participate in this study signed an informed consent. The responses of the participants were anonymous and personal details of participants were stored separately from the collected data.

\section{Instruments and Data Collection Procedure}

The data was collected by clinical nursing instructor. Clinical nursing instructor used a questionnaire that included demographic data, blood pressure measurement, and body weight measurement. Each participant was interviewed for 10-15 minutes. Body-weight and height were measured using digital scale sensitive to $0.1 \mathrm{~kg}$ and $0.5 \mathrm{~cm}$ respectively, and a non-stretch tape was fixed to a flat vertical wall. Body mass index (BMI) was calculated dividing the weight by square of height $\left(\mathrm{kg} / \mathrm{m}^{2}\right)$. The BMI values that were considered to be $<=20 \mathrm{~kg} / \mathrm{m}^{2}$, underweight; $>20$ to $25 \mathrm{~kg} / \mathrm{m}^{2}$, normal weight; $>25$ to 30 $\mathrm{kg} / \mathrm{m}^{2}$, overweight; and $>30 \mathrm{~kg} / \mathrm{m}^{2}$, obesity; all the participants wore light clothes without shoes.

BP measurement was carried out by clinical nursing instructor according to WHO standardized criteria in local clinic reference. Participants were seated in a chair, with their backs supported and their right arm bared at the level of the heart. After 5 minutes of rest, systolic blood pressure (SBP) was measured two times from the right upper arm, with at least a 2-minute interval between the two measurements. BP was recorded to the nearest $2 \mathrm{mmHg}$. The cuff was inflated until the radial pulse was no longer audible from the antecubital area, and then the cuff was deflated 2-3 $\mathrm{mm} \mathrm{Hg}$ per second while auscultation the pulse. While decreasing the cuff pressure, the onset of the sound was considered as SBP of the subject, and the disappearance of the sound was considered as Diastolic Blood Pressure (DBP). The mean value obtained from two readings was used in the analysis. For this study, hypertension was defined as SBP $>=140 \mathrm{mmHg}$, or DBP $>=90 \mathrm{mmHg}$, or previous diagnosis of hypertension, or current use of antihypertensive medication or any combination of the above (Tarver, 2014).

\section{Data Analysis Procedures}

The collected data was sorted cleaned and entered over a week, and potential errors were identified and corrective actions taken. Data entry and analysis were performed using Statistical Package for the Social Sciences (SPSS) -version 20. Descriptive statistical measures including frequency and percentages were used to describe the participants' demographics. Moreover, mean, median, range, and percentages statistics were used to calculate blood pressure measurements. The Chi square test inferential statistic was used for testing associations between of HTN and some associated risk factors. A P-value of $<0.05$ was considered to be significant.

\section{Results}

\section{Demographic Characteristics}

The sample was composed of 115 staff from a private college for health sciences in south Saudi Arabia who satisfied the criteria for inclusion in the study. The socio-demographic features of study subjects are shown in Table 1 . The majority of the participants were males $(\mathrm{n}=82 ; 71.3 \%)$, their ages between $25-34$ years $(n=71 ; 56.5 \%)$; married $(n=81 ; 70.5 \%)$ and have baccalaureate degree $(n=41 ; 35.7 \%)$.

\section{Body Weight Measurements}

The results of body weight measurements is illustrated in Table 1.The results showed that the mean BMI of the participants was $(M=27.85 ; S D=27.85)$ with range of 19.2150.04. More than two-third $(69.6 \%)$ of the participants were overweight or obese, only $30.4 \%$ had normal BMI. Moreover, Bar chart (see Figure 3) illustrated that around $33.0 \%$ of the males and $24.0 \%$ of the females are obese. Excessive BMI was more common in females $(79.0 \%$ in females compared to $66.0 \%$ in males).

\section{Prevalence of HTN}

The results of SBP and DBP measurements at two different times are shown in Table 2. Average of SBP and DBP were then calculated for these two different times. Moreover, pulse pressure and mean arterial pressure were analyzed based on that average as shown in Table 2. The results showed that average SBP was $(M=116.8 ; S D=11.1)$, average DBP $(M=$ $76 ; S D=7.8)$, and Pulse Pressure was $(M=40.8 ; S D=7.8)$. The prevalence of HTN and the distribution of the HTN between the two genders were examined. Hypertension was detected in $39.2 \%$ of the participants. Males $(55.0 \%)$ have higher prevalence of HTN than females $(33.0 \%)$.

\section{Volume 6 Issue 1, January 2017




\section{International Journal of Science and Research (IJSR) \\ ISSN (Online): 2319-7064}

Index Copernicus Value (2015): 78.96 | Impact Factor (2015): 6.391

Impact of Participants Socio-demographics on HTN

Chi square results (Table 3) showed systolic and diastolic HTN was significantly associated with gender $\left(X^{2}=15.57\right.$; $d f=3 ; P=0.01)$, age $\left(X^{2}=16.39 ; d f=9 ; P=0.01\right)$, and educational level $\left(X^{2}=30.28 ; d f=15 ; P=0.01\right)$. Similarly, diastolic HTN was significantly associated with gender $\left(X^{2}=17.83 ; d f=3 ; P=0.001\right)$, age $\left(X^{2}=12.93 ; d f\right.$ $=9 ; P=0.01)$, and educational level $\left(X^{2}=10.04 ; d f=15\right.$; $P=0.01$ ). The distribution of the participants (Table 3 ) showed that HTN is more common with those participants who are male, between ages 25-34 years, and have Baccalaureate degree. On the other hand, there were no significant association between HTN neither systolic nor diastolic with BMI of the participants $(\mathrm{P}>.05)$.

\section{Discussion}

\section{Prevalence of HTN}

A few studies in Saudi Arabia and other Arab countries have conducted on the prevalence of HTN in the faculty members. Therefore, the aim of this study was to determine the prevalence of HTN and its associated risk factors among faculty members at south Saudi Arabia. The findings of this study indicated the prevalence of HTN (using the criteria: BP > 140/90 mm Hg) was $39.2 \%$ among the faculty members. It has been reported that more than $25 \%$ of the world's adult inhabitants had HTN in the year 2000 and that this could rise to $29 \%$ by the year $2025^{(12)}$. The estimates of the HTN prevalence in the present study, therefore, are comparable to the overall prevalence of HTN internationally (4). However, the prevalence of HTN in this study is higher than those reported in other Saudi studies ${ }^{(9,10,15)}$. For instance, Bani (9) reported that the prevalence rate for essential HTN was $11.8 \%$ among the 2011 participants from eight health centers in Jazan region of Saudi Arabia. The authors of this study assumed that increasing in the westernization and urbanization of the life style in Saudi Arabia was the driving force for the increment of HTN prevalence the current study. Since HTN is a controllable disease, regular screening programs are essential to discover those people in Saudi Arabia who have the disease so as to treat them at an early stage of HTN. This approach, if adopted, may reduce the incidence and prevalence rate of HTN in Saudi Arabia.

\section{Risk Factors of HTN}

Concerning the identified HTN risk factors, the results of this study illustrated that the prevalence of HTN was significantly higher among men $(55.0 \%)$ compared to women $(33.0 \%)$. This finding is consistent with previous literature ${ }^{(9,13)}$ which reported similar finding in different regions of the world as well as in Saudi Arabia. This may be explained as follow. Usually men in Saudi Arabia engaged in unhealthy life styles such as eating heavy or fatty meals and wide availability of indoor stressful familial stimuli. Accordingly, more health care attention should be directed toward men in order to identify new cases, control the HTN in the affected individuals, and studying associated factors.

Another identified risk factor in this study was the participants' age. This finding is similar to what was reported in ${ }^{(12)}$ who found similar results in the Indian context. Usually young adults (25-34 years) in Saudi Arabia have sedentary lifestyles and do no not participate in regular physical exercise. These factors may contribute in the development of HTN among this age group. Health education programs should be carried out to increase the young adults' awareness about the importance of physical exercise. Moreover, government agencies should establish and promote play grounds for those age people to motivate them for engaging in such beneficial activities.

The last identified risk factor for HTN in this study was the educational level of the participants. The findings demonstrated that those had higher education levels (such as doctorate and master holders) had less vulnerability to develop HTN. Similar finding was reported by the previous literature $(14,16)$ which found that education significantly reduces the prevalence of HTN illness. A possible explanation of these findings is that higher level of education is frequently related with better awareness concerning healthy lifestyle and HTN associated risk factors.

There are a few limitations in this study that supposed to be considered. Fist, this study was conducted only in one private health Sciences College; therefore, the generalization of the study findings may be restricted. Future studies are recommended to include several health sciences colleges from different regions in Saudi Arabia. Second, other risk factors (such as participants' psychological status) may contribute to the development of HTN; these factors were not investigated in this study. Addressing such risk factors in further research may provide comprehensive image about the HTN associated factors in Saudi Arabia.

\section{Conclusion}

Prevalence of HTN in the south region of Saudi Arabia is relatively high and the ages of those affected individuals convey an important indicator the growing of HTN burden in this region. Planning and implementation of primary preventative strategies by the specialized health care providers in particular would be useful in the controlling of HTN in the study region. Moreover, frequent measurement and screening of blood pressure of the vulnerable cases, chiefly young male adults, might be considered as successful helpful strategies for the early detection of HTN and its associated risk factors. The current study findings highlight the importance of promoting active lifestyle among the inhabitants of Saudi community. This study contributes to advance knowledge of HTN among Saudi adults especially those working in clinical training. Therefore, it is considered as a baseline for future national and international studies intend to focus on HTN stratus among public.

However, future comprehensive epidemiological studies of the prevalence and risk factors of HTN are highly recommended. 


\section{International Journal of Science and Research (IJSR) \\ ISSN (Online): 2319-7064 \\ Index Copernicus Value (2015): 78.96 | Impact Factor (2015): 6.391}

Table 1: Sociodemographic characteristics of faculty members in Al-Ghad college- Abha $(n=115)$

\begin{tabular}{|l|l|c|c|}
\hline \multicolumn{2}{|c|}{ Characteristics } & No & $\%$ \\
\hline \multirow{4}{*}{ Sex of staff } & Male & 82 & 71.3 \\
\cline { 2 - 4 } & Female & 33 & 28.7 \\
\hline \multirow{5}{*}{ Educational Level } & 25-34 years & 71 & 61.7 \\
\cline { 2 - 4 } & $35-44$ years & 26 & 22.6 \\
\cline { 2 - 4 } & $>44$ years & 18 & 15.7 \\
\cline { 2 - 4 } & High secondary & 5 & 4.3 \\
\hline \multirow{5}{*}{ Body Mass Index (BMI) } & Diploma & 6 & 5.2 \\
\cline { 2 - 4 } & Bachelor & 41 & 35.7 \\
\cline { 2 - 4 } & Postgraduate Diploma & 8 & 7.0 \\
\cline { 2 - 4 } & Master degree & 36 & 31.3 \\
\cline { 2 - 4 } & PhD degree & 19 & 16.5 \\
\cline { 2 - 4 } & Overmal & 35 & 30.4 \\
\cline { 2 - 4 } & Obesity & 45 & 39.2 \\
\hline Marital Status & Not-Married & 35 & 30.4 \\
\cline { 2 - 4 } & Married & 81 & 29.6 \\
\hline
\end{tabular}

Table 2: Descriptive statistics of blood pressure, pulse pressure, MAP, and BMI $(n=115)$

\begin{tabular}{|c|c|c|c|c|}
\hline Parameter & Min & Max & Mean & SD \\
\hline Systolic Blood Pressure- $1^{\text {st }}$ Reading & 90 & 160 & 116.4 & 11.6 \\
\hline Systolic Blood Pressure- $2^{\text {nd }}$ Reading & 90 & 170 & 117.4 & 11.7 \\
\hline Diastolic Blood Pressure- 1 $^{\text {st }}$ Reading & 55 & 100 & 75.7 & 9.1 \\
\hline Diastolic Blood Pressure- $2^{\text {nd }}$ Reading & 50 & 100 & 76.7 & 8.2 \\
\hline Average Systolic Blood Pressure & 95 & 155 & 116.8 & 11.1 \\
\hline Average Diastolic Blood Pressure & 55 & 95 & 76.0 & 7.8 \\
\hline Pulse Pressure & 20 & 75 & 40.8 & 7.8 \\
\hline Mean Arterial Pressure (MAP) & 68.3 & 115 & 89.6 & 8.3 \\
\hline Body Mass Index (BMI) & 19.21 & 50.04 & 27.9 & 4.8 \\
\hline
\end{tabular}

Table 3: Distribution of the Studied Group according to Risk Factors of Hypertension $(n=115)$

\begin{tabular}{|c|c|c|c|c|c|c|c|}
\hline \multirow{2}{*}{\multicolumn{2}{|c|}{ Risk Factor }} & \multicolumn{2}{|c|}{$\begin{array}{c}\text { Status of Hypertension } \\
\text { SBP }\end{array}$} & \multirow[t]{2}{*}{$\mathrm{p}$} & \multicolumn{2}{|c|}{$\begin{array}{c}\text { Status of Hypertension } \\
\text { DBP }\end{array}$} & \multirow[t]{2}{*}{$\mathrm{P}$} \\
\hline & & Not-Hypertensive & Hypertensive & & Not-Hypertensive & Hypertensive & \\
\hline \multirow{2}{*}{ Sex } & Male & 58 & 24 & \multirow{2}{*}{$\begin{array}{c}<.05 \\
*\end{array}$} & 64 & 18 & \multirow[b]{2}{*}{$<.05^{*}$} \\
\hline & Female & 32 & 1 & & 31 & 2 & \\
\hline \multirow{3}{*}{ Age (Years) } & $25-34$ years & 59 & 12 & \multirow{3}{*}{$\begin{array}{l}<.05 \\
*\end{array}$} & 61 & 10 & \multirow[t]{3}{*}{$<.05^{*}$} \\
\hline & $35-44$ years & 21 & 5 & & 21 & 5 & \\
\hline & $>44$ years & 10 & 8 & & 13 & 5 & \\
\hline \multirow{6}{*}{$\begin{array}{l}\text { Educational } \\
\text { Level }\end{array}$} & High secondary & 4 & 1 & \multirow{6}{*}{$\begin{array}{l}<.05 \\
*\end{array}$} & 4 & 1 & \multirow{6}{*}{$<.05^{*}$} \\
\hline & Diploma & 6 & 0 & & 6 & 0 & \\
\hline & Bachelor & 32 & 9 & & 34 & 7 & \\
\hline & Postgraduate Diploma & 6 & 2 & & 7 & 1 & \\
\hline & Master degree & 32 & 4 & & 29 & 7 & \\
\hline & PhD degree & 10 & 9 & & 15 & 4 & \\
\hline \multirow{2}{*}{ BMI } & Normal & 26 & 9 & \multirow[t]{2}{*}{$>.05$} & 29 & 6 & \multirow[t]{2}{*}{$>.05$} \\
\hline & Obese \& Over Wight & 64 & 16 & & 66 & 14 & \\
\hline
\end{tabular}

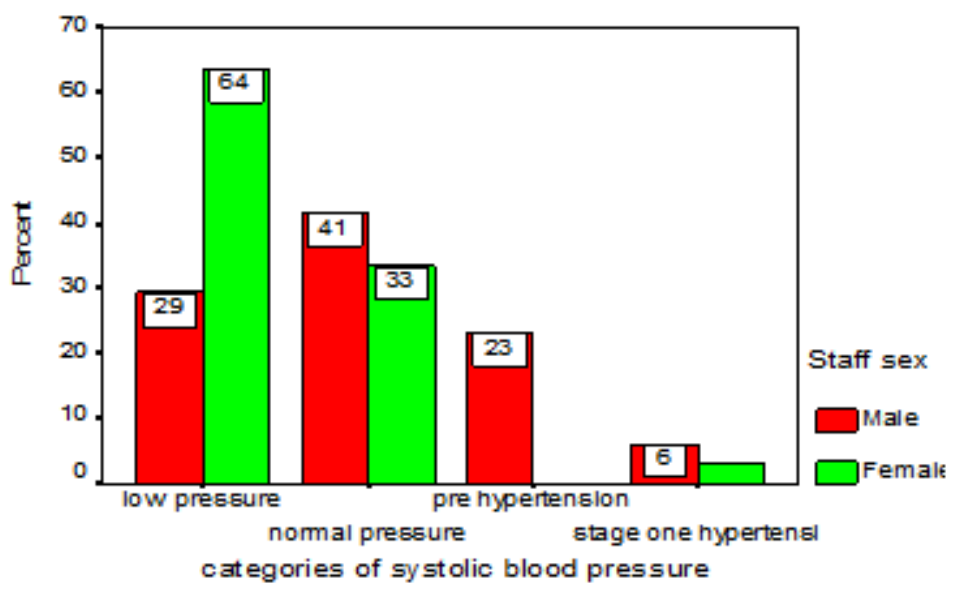

Figure 1: Bar chart showing pattern of systolic blood pressure according to sex

Volume 6 Issue 1, January 2017 www.ijsr.net

Licensed Under Creative Commons Attribution CC BY 


\section{International Journal of Science and Research (IJSR) \\ ISSN (Online): 2319-7064}

Index Copernicus Value (2015): 78.96 | Impact Factor (2015): 6.391

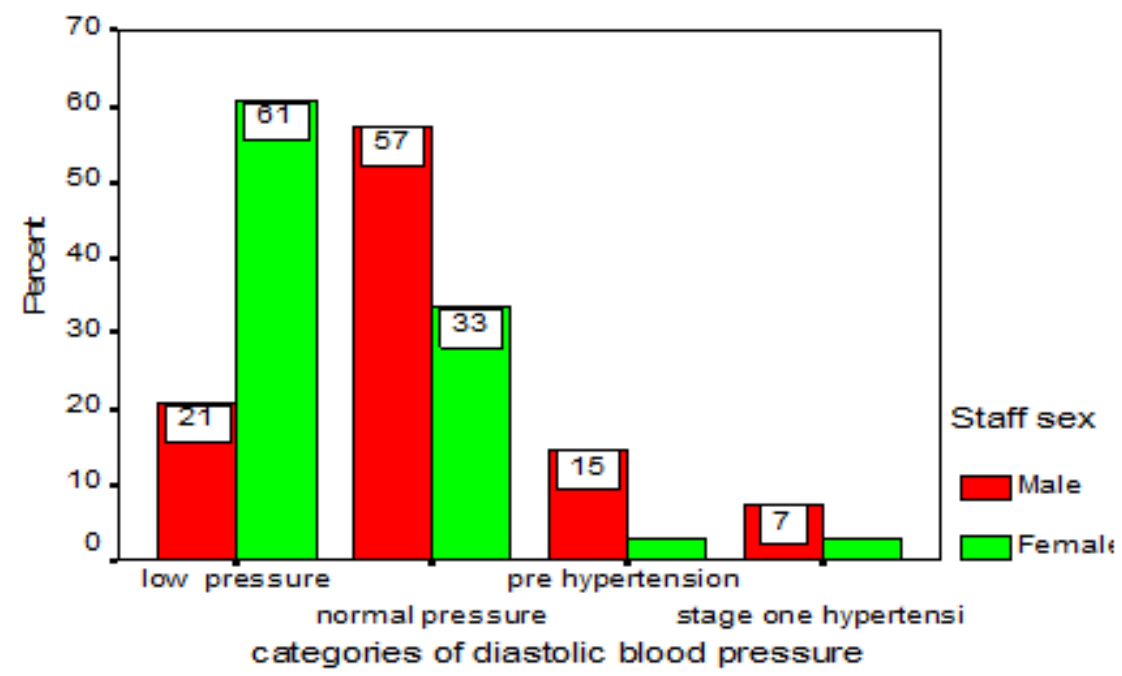

Figure 2: Bar chart showing pattern of diastolic blood pressure according to sex

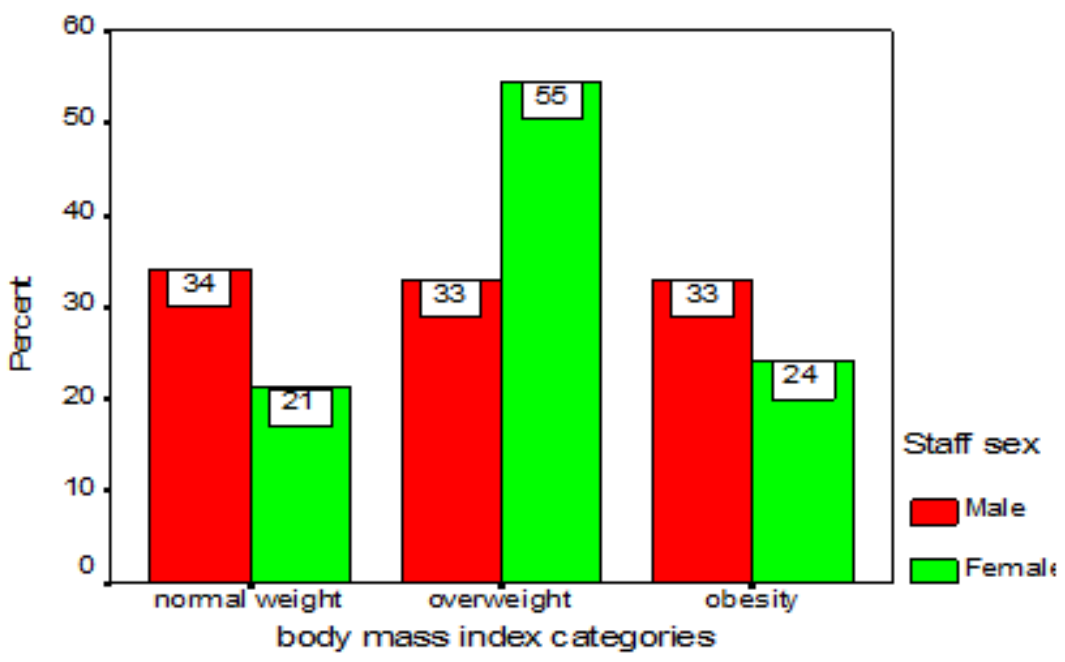

Figure 3: Bar chart showing pattern of BMI according to sex

\section{References}

[1] Persell, S. (2011). Prevalence of Resistant Hypertension in the United States, 2003-2008. Hypertension, 57(6), 1076-1080. http://dx.doi.org/10.1161/hypertensionaha.111.17030 $\underline{8}$.

[2] DiBona, G. (2013). Sympathetic Nervous System and Hypertension. Hypertension, 61(3), 556-560. http://dx.doi.org/10.1161/hypertensionaha.111.00633.

[3] Verdecchia, P., Angeli, F., Mazzotta, G., Garofoli, M., Ramundo, E., \& Gentile, G. et al. (2012). DayNight Dip and Early-Morning Surge in Blood Pressure in Hypertension: Prognostic Implications. Hypertension, 60(1), 34-42. http://dx.doi.org/10.1161/hypertensionaha.112.19185 $\underline{8}$.

[4] Tarver, T. (2014). HEART DISEASE AND STROKE STATISTICSâe“"2014 UPDATE: A REPORT FROM THE AMERICAN HEART ASSOCIATION. Journal Of Consumer Health On The Internet, 18(2), 209-209. http://dx.doi.org/10.1080/15398285.2014.902284.

[5] Marwa Tuffaha, A. (2015). Cost of Diabetes in the Kingdom of Saudi Arabia, 2014. Journal Of Diabetes \& Metabolism, 06(08).
[6] http://dx.doi.org/10.4172/2155-6156.1000575.

[7] Al-Haqwi, A., Al-Nasir, M., Alotaibi, S., Hamad, B., Masaudi, E., \& Ahmad, N. (2015). Obesity and overweight in a major family practice center, central region, Saudi Arabia. Saudi J Obesity, 3(1), 12. http://dx.doi.org/10.4103/2347-2618.158690.

[8] Alquaiz, A., Khoja, T., Alsharif, A., Kazi, A., Mohamed, A., \& Al Mane, H. et al. (2015). Prevalence and correlates of anaemia in adolescents in Riyadh city, Kingdom of Saudi Arabia. Public Health Nutr., 18(17), 3192-3200. http://dx.doi.org/10.1017/s1368980015001214.

[9] Alkhalaf, M., Edwards, C., \& Combet, E. (2015). Current reported and observed hypertension status, sodium intake practices and body composition of adults in Riyadh city, Saudi Arabia. Proceedings of The Nutrition Society, 74(OCE1). http://dx.doi.org/10.1017/s0029665115000373.

[10]Bani, I. (2011). Prevalence and related risk factors of Essential Hypertension in Jazan region, Saudi Arabia. Sudanese Journal Of Public Health, 6(2), 45-50.

[11]El Bcheraoui, C., Memish, Z., Tuffaha, M., Daoud, F., Robinson, M., \& Jaber, S. et al. (2014). Hypertension and Its Associated Risk Factors in the Kingdom of Saudi Arabia, 2013: A National Survey. International Journal Of Hypertension, 2014, 1-8. http://dx.doi.org/10.1155/2014/564679.

\section{Volume 6 Issue 1, January 2017 www.ijsr.net}




\section{International Journal of Science and Research (IJSR) \\ ISSN (Online): 2319-7064 \\ Index Copernicus Value (2015): 78.96 | Impact Factor (2015): 6.391}

[12] Muzaffar Iqbal,. (2011). Clinical Perspective on the Management of Hypertension. IJCM, 1. http://dx.doi.org/10.4137/ijcm.s5475

[13]Fedacko, J., Singh, R., Pella, D., Ghosh, S., Begom, R., \& Tumbi, Z. et al. (2011). PREVALENCE AND RISK FACTORS FOR PREHYPERTENSION AND HYPERTENSION IN FIVE INDIAN CITIES. Journal Of Hypertension, 29, e440. http://dx.doi.org/10.1097/00004872-20110600101321.

[14] Tayem, Y., Yaseen, N., Khader, W., Abu Rajab, L., Ramahi, A., \& Saleh, M. (2012). Prevalence and risk factors of obesity and hypertension among students at a central university in the West Bank. Libyan Journal Of Medicine, $7(0)$. http://dx.doi.org/10.3402/ljm.v7i0.19222.

[15] Ting, N. (2014). Prevalence and Factors Associated with Depression among Rural Communities in Negeri Sembilan, Peninsular Malaysia. JSRR, 3(12), 16891702. http://dx.doi.org/10.9734/jsrr/2014/10369.

[16] Tailakh, A., Evangelista, L., Mentes, J., Pike, N., Phillips, L., \& Morisky, D. (2013). Hypertension prevalence, awareness, and control in Arab countries: A systematic review. Nursing \& Health Sciences, 16(1), 126-130. http://dx.doi.org/10.1111/nhs.12060.

[17] Narayan, K., \& Rashid, A. (2007). Blood Pressure Patterns and the Prevalence of Hypertension and its Associated Factors in a Rural Community in Northern Malaysia. Malaysian Journal of Public Health Medicine, 7(1), 14-19. 